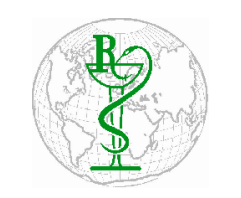

INDO GLOBAL JOURNAL OF

PHARMACEUTICAL SCIENCES

ISSN 2249- 1023

\title{
Good Storage Practice in Pharmaceutical Manufacturing Plants in Khartoum State of Sudan
}

\author{
Gamal Osman Elhassan ${ }^{1,2 *}$, Baha Eldin Suliman Khalid ${ }^{3}$, Abu Bakr Abd Alrouf ${ }^{1}$, \\ Jawed Akhtar ${ }^{1}$, Riyaz Khan ${ }^{1}$, Jiauddin Khan ${ }^{4}$, Khalid Omer Alfarouq ${ }^{5}$ \\ ${ }^{1}$ Unaizah College of Pharmacy, Qassim University, Qassim, KSA \\ ${ }^{2}$ Omdurman Islamic University (OIU), Omdurman-Sudan \\ ${ }^{3}$ Pharmaceutical Services Fellowship,Sudanese Medical Specialization Board, Khartoum- Sudan \\ ${ }^{4}$ Management \& Science University, Selangoor, Malaysia \\ ${ }^{5}$ Ministry of Health Khartoum State, Khartoum, Sudan
}

Address for Correspondance: Gamal Osman Elhassan, go.osman@qu.edu.sa , gamaosma63@yahoo.com

\begin{abstract}
The survey employed key informant interviews to generate quantitative data. A questionnaire based on the seven main study areas was used to collect data. The data were quantitative in nature and were analyzed using descriptive statistics. The results of the analysis show that pharmaceutical manufacturers have a strong incentive to maintain good storage practices that give better public health outcomes. However, the analysis also shows that manufacturers faces many constraints to implement good storage practices especially in the sides of personnel qualification (36.9\% failure), warehouses quality ( $22.8 \%$ failure), and products recall (38.1\% failure). This study concludes that pharmaceutical manufacturers have a strong incentive to engage in responsible business practices, where these are financially visible. However, manufacturers have shown weak incentives to improve the qualification of their personnel. () 2014 iGlobal Research and Publishing Foundation. All rights reserved.
\end{abstract}

KEYWORDS: GSP; Pharmaceutical Manufacturing Plants; Guidelines.

\section{INTRODUCTION}

In general, the pharmaceutical industry or sector in any country consists of different companies that manufacture pharmaceuticals, package pharmaceuticals, serve the public in dispensing pharmaceuticals, and manage employers and employees and various consumer benefit schemes including insurance products [1] for Sudan, the pharmaceutical sector comprises of producers of drugs, wholesalers, retailers and consumers. According to the National Medicines and Poisons Board (2012), the pharmaceutical market in Sudan on the demand side was worth about $\$ 500$ million in the year 2012 , 30\% of this was covered by the local manufacturers. The current number of pharmaceutical manufacturers is 22 (NMPB, 2012). In the side of supply of pharmaceutical products, the major role is played by the private sector. Although the share of the local pharmaceutical manufacturers in the wholesale market is smaller than other players, still it is clearly an important part of the supply chain of pharmaceutical products to the ultimate consumers of drugs and other pharmaceutical products. The majority 
of those manufacturers are clustered in Khartoum State. Local pharmaceutical manufacturers supply medicines and other pharmaceutical products to over registered pharmacies and wholesalers operating in small towns and villages across the country.

An important part in the supply of good quality pharmaceutical products is the good storage practices (GSPs). GSPs are a set of standards which are started and intended to ensure the quality, safety and efficacy of the products. GSPs are important to ensure availability of safe, effective and high quality drugs for all consumers. The main goals of GSPs are to protect stored items from loss, damage and theft or wastage and to manage the reliable movement of supplies from source to user in the least expensive way and without significant wastage or theft [2]. Many medicines require special storage conditions. Therefore, it is important to control light, heat, moisture and gases in the environment that may affect medicines. To overcome these problems medicines must be stored in amber tight and moisture resistant containers [3]. GSPs of pharmaceuticals till the time of distribution, ensure the delivery of the product in a good quality, safety and efficiency conditions according to NDP 2005-2009 (Quality assurance) [4]. Therefore, failure of local pharmaceutical manufacturers to comply with GSPs specifications can result in very serious consequence including recall. Unfortunately hot climates, discontinuation of power supply and capitalization costs are the major factors that deteriorate the efficiency of storage system management in Sudan [4]. Given the considerable gap in the knowledge of the critical role of GSPs in assurance of quality of medicines, this study was conducted to examine local pharmaceutical manufacturers' incentives to bind to GSPs guidelines which include assurance of good storage practices and, consequently, assurance of quality of medicines.

\section{MATERIALS\& METHODS}

This study presents a quantitative survey conducted in Sudan, Khartoum State. A face-to-face structured interview survey methodology was employed to collect data from seven local pharmaceutical manufacturing plants. The quantitative methodology was used to weight local pharmaceutical manufacturers' strengths and weaknesses within the pharmaceutical good storage practices through in-house key informant interviews to generate quantitative data.

A questionnaire was developed based on WHO level 2 indicators for assessment of GSP. The questionnaire used in this research was in Arabic and consisted of seven parts.
Part I: Measured qualified personal management. Part II: Measured storage requirements Part II: Measured quality of warehouses Part IV: Measured documentation system Part V: Measured returned goods Part VI: Measured dispatch and transport. Part VII: Product recall.

The study was conducted in Khartoum state during the period from Nov. 2012 to April 2013. In Khartoum there are twenty four warehouses specially designed for storage of pharmaceuticals prior to distribution. Seven Warehouses of pharmaceutical firms were selected. Interviews were conducted at the premises of the local pharmaceutical manufacturers by the first author who is a pharmacist. The author engaged in face-to-face interviews to get a better insight into GSPs activities of the participants. Based on the interviews, the authors rated the incentives for local pharmaceutical manufacturers in each category to act to meet the key needs identified in WHO level 2 indicators for assessment of GSPs (ratings were Yes or No). Inclusion criteria was that key informants should be part of senior management and should have worked with the company for about 5 years or more and be willing to participate in the survey.

Before starting data collection, a formal permission letters were issued by research committee of S.M. Specialization board addressed to whom it may concern explaining the aim of the study. Interviewees were informed about the academic purposes of the study, and consequences of the data. They have been also informed that data will be fairly processed and used only for the purpose of this study.

\section{RESULTS\& DISCUSSON}

Most of the local pharmaceutical manufacturers are complying with GSPs regarding storage requirements specifications and dispatch and transport specifications, while weak compliance was observed regarding personnel qualifications and product recall specifications (see Tables 1 below).

Also all interviewees stated that their manufacturing plants suffer from financial problems due to lack of political commitment, while most of them admitting facing difficulties in implementing personnel hygiene due to poor awareness of the working personnel about the importance of sanitation and hygiene, especially those in direct contact with raw materials throughout the manufacturing operation processes (see Table 2 below). 
Indo Global Journal of Pharmaceutical Sciences, 2014; 4(2): 100-102

Table 1: Percentage of failure to comply with WHO level 2 indicators for assessment of GSPs

\begin{tabular}{lc}
\hline WHO level 2 indicators for assessment of GSPs & Failure percentage \\
\hline Personnel qualifications & 36.9 \\
Facilities and premises (warehouse quality) & 22.8 \\
Storage requirements specifications & 3.8 \\
Product recall specifications & 38.1 \\
Dispatch and transport specifications & 3.9 \\
Overall & $\mathbf{1 5 . 1}$ \\
\hline
\end{tabular}

Table 2: Interviewees perspectives regarding difficulties facing implementation of GSPs

\begin{tabular}{lc}
\hline Difficulty & Occurrence percentage \\
\hline Difficulty in implementing personnel hygiene & 85.7 \\
Lack of political commitment & 100.0 \\
Weakness of in-job training programs & 71.4 \\
Lack of close supervision and follow-up & 71.4 \\
Financial problem & 57.1 \\
Time over problem & 28.5 \\
\hline
\end{tabular}

\section{CONCLUSON}

This study revealed that all local pharmaceutical manufacturers had a strong allegation that they are willing for maintaining good storage practices even though it was costly to do so. However, this is not reflected in either their personnel qualification level or their product recall system. Local manufacturers do not conduct routine post-market surveillance and do not maintain good product recall systems. It was obvious that most of the local pharmaceutical manufacturers were not committed to doing so, and they solely rely on the National Laboratory to verify the quality of the medicines they sell.

Also the study revealed that although some local pharmaceutical manufacturers are committed to providing good transport services. Even though it results in an increase in their expenditure, it makes their products accessible to many customers and improves turnover. Most of the manufacturers, on the other hand, are not committed to providing transport services. They do not necessarily involve themselves in the business of distribution, since some other manufacturers send sales vans around to distribute. In providing regional distribution points and implementing a scheduled delivery system, the local manufacturers committed to providing transport services had a partial incentive to do so. The main incentive appears to be to increase in sales volume and increased ability to compete with other suppliers with significant market share in rural areas. Other manufacturers unable to engage in a scheduled delivery system or provision of regional distribution points seems do not engaged in that due to lack of capacity and inadequate working capital, and low returns from previous attempts leading to their discontinuation of those operations.

Also it was obvious from results presented in Table 2 that the plants managers were challenged with difficulties in the implementation of sanitation and hygiene specially personnel hygiene. This is referring to poor awareness of the personnel about the important of sanitation and hygiene, especially for that personnel who handles the medicine.

\section{REFERENCES}

1. Rentmeester, C.A. and Garis, R.I. Rebates and spreads: Pharmacy benefit management practices and corporate citizenship. Journal of Health Politics, Policy, and Law 33(5): 943-963, rebuttal to commentary 975-978, October 2008.

2. Quick, J.D, et.al,1997 Management of medical store .2nded .west: Kumarian press, (chapter 23), pages 342-361.

3. World health organization technical report series, NO908,2003..available at www.who.com accessed on 20/10/ 2012

4. National drug policy,2005-2009, general directorate of pharmacy.

Indo Global Journal of Pharmaceutical Sciences( ISSN 22491023 ; CODEN- IGJPAI; NLM ID: 101610675) indexed and abstracted in EMBASE(Elsevier), SCIRUS(Elsevier),CABI, CAB Abstracts, Chemical Abstract Services(CAS), American Chemical Society(ACS), Index Copernicus, EBSCO, DOAJ, Google Scholar and many more. For further details, visit 